\title{
118. Morphological Inconsistency in Liver Cells in Culture
}

\author{
By Tohru OKIGAKI and Shirley G. QuAN \\ Pasadena Foundation for Medical Research, Pasadena, California, 91101, U. S. A. \\ (Comm. by Sajiro Makino, M. J. A., Sept. 12, 1974)
}

In general, the growing cells in a culture system are known to possess tissue specific morphology, mainly either epithelial or fibroblastic form. However, this is not necessarily true due to the flexibility of cell structure and occasional alterations of morphology occurring under certain conditions. The following environmental factors which are influential to the alteration of cell morphology can be considered:

(a) aging of cells ${ }^{1,2)}$; (b) composition of culture media ${ }^{2)}$; (c) quality and quantity of serum in media ${ }^{3)}$; (d) addition of chemicals, such as hormones ${ }^{3,4)}$; and (e) substrate of containers, plastic or glass. ${ }^{2)}$

Hence, the morphology of cultured cells should be expected as a result of physiological negotiation between the original tissue cell form and the environmental factors.

Recently, morphological transformation of cells without any environmental change has also been observed in various cultures. The cellular transformation from epithelialtype to fibroblastictype in adult rabbit lung cells has been observed in our laboratory. ${ }^{5)}$ The morphological transformation, on the contrary, from the spindleshaped cells with oval nuclei to the polygonal epithelium-like cells with more rounded nuclei was reported by De La Maza and Yunis ${ }^{1)}$ in the cell culture of field vole embryos.

Since the hepatocytes of the liver tissue are typically epithelial in shape, it might be safe to say that the morphology of cultured hepatocytes would be assumed as epithelioid. In fact, the liver cells are epithelioid in the majority of established cell lines.

However, as an exception, Kaighn and Prince ${ }^{6)}$ have reported that their human hepatocyte cultures maintaining liver specific characteristics are nothing like epithelial, but fibroblastic in appearance.

This interesting finding gave us an opportunity to make further analyses of liver-originated cells, whether they will morphologically alter in the early stage of culture, or not.

Materials and methods. The livers from three 12 day-old-male Wistar rats were minced and dissociated with our own dissociation solution. The dissociation solution is made of a mixture of $0.05 \%$ 
collagenase, $0.1 \%$ hyaluronidase, $0.1 \%$ trypsin, $2.0 \mathrm{~g} \mathrm{NaCl}, 1 \%$ chicken serum, and $1.43 \mathrm{~g}$ MES and $1.22 \mathrm{~g}$ TES as a buffer in $1000 \mathrm{ml}$ of $\mathrm{Ca}, \mathrm{Mg}$ free Hank's balanced salt solution.

A primary culture after two weeks in Ham's F-12 medium supplemented with $10 \%$ fetal calf serum showed a mixed culture of both hepatocyte-like epithelial and non-epithelial cells (Fig. 1). A small coverslip with the growing cells was placed under an inverted microscope and non-epithelial cells were mechanically eliminated with a sharp steel pin.

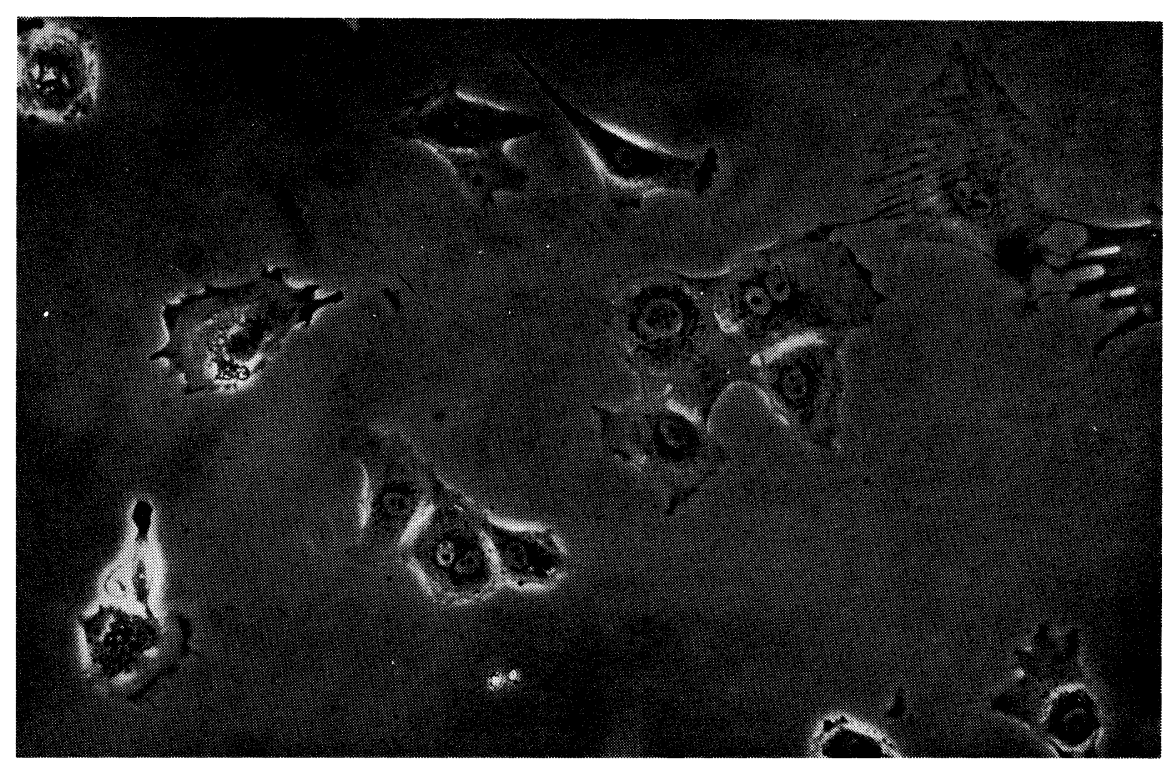

Fig. 1. A rat liver primary culture (14 days), showing both epithelial and non-epithelial cells. $\times 800$

After this time-consuming work, the epithelial cell colonies were still maintained for some time in the same condition. Then, either clonal isolation by using a metal cylinder and/or additional treatment with the hydrocortisone $(20 \mathrm{mg} / \mathrm{l})$ containing medium were performed to obtain a homogeneous population of epithelial cells.

However, it is obvious that even after this procedure with gentle care, the culture will often be terminated with non-epithelial cells.

A time-lapse cinematography, to trace the possible morphological transformation of liver cells was done at the Biological Photography Laboratory.

Results and discussion. As a result, the observation was made that some of the typical epithelial cells in early passages were able to change their morphology in a relatively short period of time (Fig. 2). 
One of the rat liver cell lines (designated as RL-11), originated from epithelial cells, was not quite epithelial in later passages, and biochemical assay for tyrosine transaminase showed no liver specific response. However, at the same time, histochemical staining for the demonstration of tyrosine aminotransferase by Thompson and Tomkins' method $^{7)}$ showed weak but positive stain for this liver specific enzyme. This cell line had been growing in both arginine-free and hydrocortisone containing media. In addition to this, the administration of a hepatocarcinogen thioacetamide onto the culture $(50 \mathrm{mg} / 1$ for a week) showed structural damages, such as swelling and deformation of nucleolei in RL-11 cells. This nucleolar reaction resembled the effect of thioacetamide on intact hepatocytes of rat livers. ${ }^{2}$ )

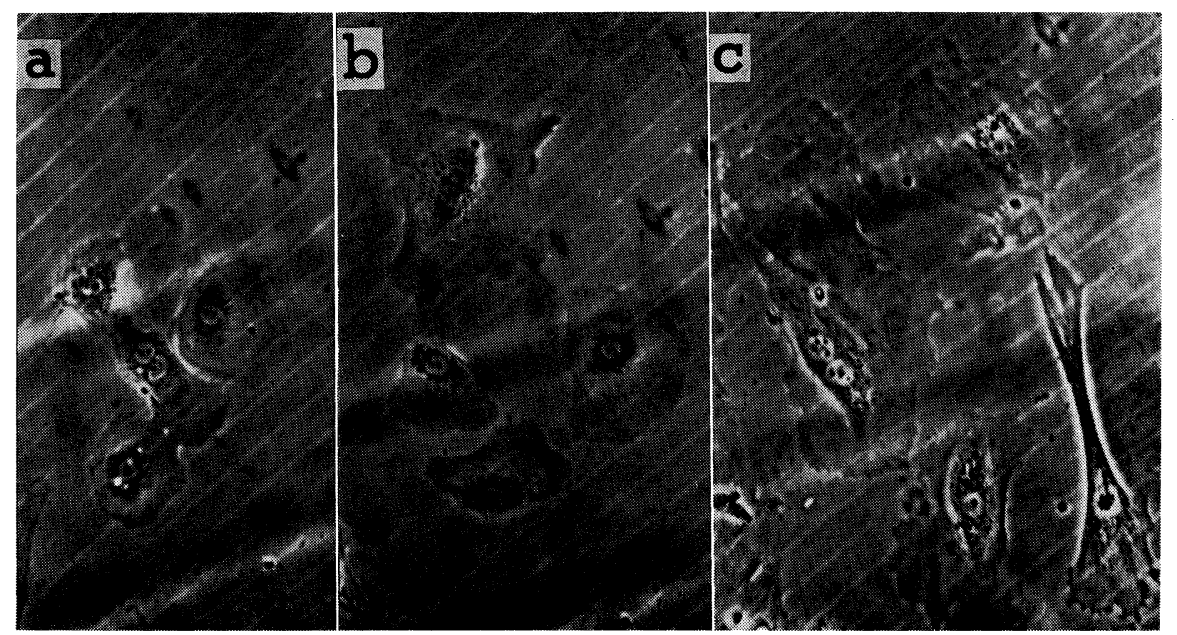

Fig. 2. Time-lapse photomicrography of morphologically transforming liver cells. $\times 800$

a: 4th-day-culture at passage 2. b: 1 day later. Note cytoplasmic spreads of cells. c: 4 days later. Note fibroblastic appearance of cells.

Thus, it would be safe to state that this cell line derived from the rat liver is of hepatic origin but lacks epithelial morphology and some liver specific characteristics.

A very similar type of morphological transformation has also been observed by us in human liver cultures. Ultrastructural alteration of human liver cells by electron microscopy indicated that the breakdown of rough endoplasmic reticulum would be related to the morphological changes of the cells in relatively early stages in cultivation.

It is, then suggested that the following categories can be speculated for the classification of the cells in liver cultures: 
(1) there are typical epithelial cells with liver specific characteristics; (2) there are near-epithelial or non-epithelial cells transformed from hepatocytes, but do not retain most characteristics; and (3) there are non-epithelial, non-hepatocytic cells from the beginning of cultivation.

The functional and structural nature of morphologically transformed liver cells has not been well known and is a question to be answered especially with reference to cellular differentiation.

Acknowledgements. The authors are deeply indepted to Dr. Sajiro Makino, Professor Emeritus, Hokkaido University for his continuous encouragements and going through this manuscript. This investigation was supported by Public Health Service Grant No. CA13376-02 from the National Cancer Institute.

\section{References}

1) De La Maza, L. M., and J. J. Yunis (1974) : Explt. Cell Res., 84, 175-182.

2) Okigaki, T. (1974): Unpublished.

3) Gerschenson, L. E. et al. (1972) : Exp. Cell Res., 71, 49-58.

4) Hsie, A. W. et al. (1971) : Proc. Nat. Acad. Sci. U. S., 68, 1648-1652.

5) Rounds, D. E. (1974) : Personal communication.

6) Kaighn, E. M., and A. M. Prince (1971): Proc. Nat. Acad. Sci. U. S., 68, 2396-2400.

7) Thompson, E. B., and G. M. Tomkins (1971): J. Cell Biol., 49, 921-927.

8) Okigaki, T., and A. L. Koehler (1972) : J. Cell Biol., 55, 193a.

9) Okigaki, T. et al. (1974) : In Vitro, 9, 360. 